\title{
Early childhood predictors of anxiety in early adolescence
}

Article

Accepted Version

Hudson, J. L., Murayama, K., Meteyard, L., Morris, T. and Dodd, H. F. (2019) Early childhood predictors of anxiety in early adolescence. Journal of Abnormal Child Psychology, 47 (7). pp. 1121-1133. ISSN 0091-0627 doi:

https://doi.org/10.1007/s10802-018-0495-6 Available at https://centaur.reading.ac.uk/80429/

It is advisable to refer to the publisher's version if you intend to cite from the work. See Guidance on citing.

To link to this article DOI: http://dx.doi.org/10.1007/s10802-018-0495-6

Publisher: Springer

All outputs in CentAUR are protected by Intellectual Property Rights law, including copyright law. Copyright and IPR is retained by the creators or other copyright holders. Terms and conditions for use of this material are defined in the End User Agreement.

\section{www.reading.ac.uk/centaur}

\section{CentAUR}

Central Archive at the University of Reading 
Reading's research outputs online 
This is the authors' copy of an accepted manuscript:

Hudson,J.L. Murayama, K., Meteyard, L., Morris, T., \& Dodd, H.F. (in press). Early childhood predictors of anxiety in early adolescence. Journal of Abnormal Child Psychology.

Journal homepage: https://link.springer.com/journal/10802 


\begin{abstract}
This longitudinal study examined a multitude of early childhood predictors of anxiety symptoms and disorders over an 8-year period. The purpose of the study was to identify early life predictors of anxiety across childhood and early adolescence in a sample of at-risk children. The sample included 202 preschool children initially identified as behaviorally inhibited or uninhibited between the ages of 3 years 2 months and 4 years 5 months. Temperament and familial environment variables were assessed using observation and parent report at baseline. Anxiety symptoms and disorders were assessed using questionnaires and diagnostic interviews at baseline (age 4), and at age 6, 9 and 12 years. In line with our hypotheses, the findings showed that preschool children were more likely to experience anxiety symptoms and disorders over time i) when the child was inhibited, ii) when there was a history of maternal anxiety disorders or iii) when mothers displayed high levels of overinvolvement. Further, the study identified a significant interaction effect between temperament and maternal overvinvolvement such that behaviorally inhibited preschoolers had higher anxiety symptoms at age 12 , only in the presence of maternal overinvolvement at age 4 . The increased risk of anxiety in inhibited children was mitigated when mothers demonstrated low levels of overinvolvement at age 4 . This study provides evidence of both additive and interactive effects of temperament and family environment on the development of anxiety and provides important information for the identification of families who will most likely benefit from targeted early intervention.
\end{abstract}

Keywords: temperament; anxiety; internalising; parenting; attachment; behavioral inhibition. 


\section{Early life predictors of anxiety in early adolescence}

Anxiety disorders are highly prevalent in children and adolescents, negatively impact multiple domains of functioning and have ominous long-term implications for adjustment (Polanczyk, Salum, Sugaya, Caye, \& Rohde, 2015; Rapee, Schniering, \& Hudson, 2009). In addition to their high prevalence, anxiety disorders have the earliest age of onset compared to other major mental health disorders and, if left untreated, persist into adulthood resulting in significant personal and societal costs (Erskine et al., 2015; Merikangas et al., 2010). Despite well-documented efficacy of treatments for child anxiety (James, James, Cowdrey, Soler, \& Choke, 2015), research into the causes of these disorders remains comparatively limited. Understanding the factors that place an individual at risk of anxiety, early in life, can provide valuable information regarding the ultimate prevention of anxiety. Of particular interest are risks that occur during the preschool years, the period prior to the typical age of onset.

One of the key early life predictors of anxiety disorders is a behaviorally inhibited temperament. Kagan and colleagues defined Behavioral Inhibition (BI) as reactions of withdrawal, wariness, avoidance and shyness in unfamiliar situations and suggest that roughly $10-15 \%$ of infants can be identified as BI (Garcia Coll, Kagan, \& Reznick, 1984). Findings from longitudinal studies of BI children suggest that an inhibited child is significantly more likely than an uninhibited child to have an anxiety disorder at baseline and also more likely to develop an anxiety disorder over time (Frenkel et al., 2015; Hirshfeld et al., 1992; Hudson, Dodd, \& Bovopoulos, 2011; Hudson \& Dodd, 2012; Prior, Smart, Sanson, \& Oberklaid, 2000; Schwartz, Snidman, \& Kagan, 1999). Research consistently demonstrates that BI marks an increased risk for anxiety disorders, in particular, a sevenfold increased risk for social anxiety disorder (Clauss \& Blackford, 2012).

Alongside BI, a number of developmental psychopathology models identify key familial environments that increase a child's risk for disorder (Dodd, Hudson, \& Rapee, 2017). Some of the most widely studied familial factors include parental anxiety and parenting related constructs such 
as over-involvement, negativity, and attachment security. In addition to the genetic transmission of anxiety from parent to child, parent anxiety may impact the development of offspring anxiety via modelling or verbal transmission of threat and coping. An anxious parent may be more likely to model anxious behaviors or provide the child with information that increases perceptions of threat and avoidance behavior. In support of this, a number of studies have shown the impact of a mother's fearful facial expressions, behaviors or communications on child avoidance and fear (Dubi, Rapee, Emerton, \& Schniering, 2008; Percy, Creswell, Garner, O’Brien, \& Murray, 2016). Consistent with these findings, using data from the sample reported in the current study, maternal anxiety disorders measured at age 4 significantly predicted child anxiety at age 6 and 9, even after controlling for the child's anxiety at age 4 (Hudson \& Dodd, 2012). Taken together, these results suggest that maternal anxiety plays an important role in predicting child anxiety over time.

Another familial environment variable that may shape the development of anxiety is parental overinvolvement (Ollendick \& Grills, 2016). A child whose parent is overinvolved or controlling is likely to have reduced opportunities for exposure to novelty or potentially difficult situations, thereby reducing the child's opportunities to determine accurate information about threat and coping. In a review of parenting behaviors associated with anxiety in young people, McLeod, Wood and Weisz (2007) reported that controlling, overinvolved parenting behaviors were more strongly associated with anxiety in children than other aspects of parenting such as negativity or rejection. Parenting that is low in warmth has been inconsistently associated with child anxiety and accounts for a smaller proportion of variance in anxiety symptoms. This construct is more strongly associated with externalizing behavior (Asbrand, Hudson, Schmitz, \& Tuschen-Caffier, 2017; Rubin, Burgess, Dwyer, \& Hastings, 2003). In support of these findings, our longitudinal work confirmed that, maternal overinvolvement, but not negativity was associated with increased anxiety disorders and symptoms at age 6 and 9 years for inhibited and uninhibited children (Hudson \& Dodd, 2012; Hudson, Dodd, Lyneham, \& Bovopoulous, 2011). Others have also shown the longitudinal association between parental overprotection and anxiety over time (Johnson et al., 2016; Muris, 
Brakel, Arntz, \& Schouten, 2011; Rubin, Burgess, \& Hastings, 2002).

The absence of a secure attachment relationship between infant and caregiver has been described as a non-specific risk factor for both internalising and externalising disorders in children (Ainsworth, Blehar, Waters, \& Wall, 2015). When a child is unable to reliably elicit caregiver attention when needed, the child then develops an internal working model in which they may view themselves as incapable, the world as unsafe and others as untrustworthy, placing them at risk for anxiety disorders (Manassis, 2001). In a meta-analysis examining the relationship between attachment security and child anxiety specifically, Colonnesi and colleagues (2011) concluded that attachment security showed a moderate relationship $(\mathrm{r}=.30)$ with child anxiety, particularly during adolescence. In contrast, in our previous work, mother-child attachment assessed during the strange situation at age 4 was not predictive of later anxiety symptoms and disorder (Hudson \& Dodd, 2012; Hudson et al., 2011). More recently however, Lewis-Morrarty and colleagues (2015) examined anxiety symptoms in adolescents predicted by temperament and attachment at age 14 months demonstrating that attachment moderated the relation between temperament and social anxiety in adolescents. That is inhibited children, particularly boys, with an insecure attachment had an increased risk for social anxiety.

In further support of the role of the familial environment in the development of child anxiety, a recent study using a powerful 'children of twins' design, demonstrated that transmission of anxiety from parent to child was almost entirely explained by direct environmental transmission (Eley et al., 2015). Research that rigorously assesses the familial environment using multiple methods of assessment is essential in order for us to obtain knowledge about environmental transmission of these frequent and impairing disorders. Identification of environmental factors can then lead to the development of enhanced prevention programs. One of the current knowledge gaps is the impact of these early life factors on anxiety during adolescence, given this is a period of increased onset for anxiety disorders. Only a handful of studies have examined adolescent outcomes for inhibited children (Chronis-Tuscano et al., 2009; Lewis-Morrarty et al., 2015; Schwartz et al., 1999) and 
although some have identified an interaction between BI and parenting factors predicting social anxiety, we have limited knowledge about these variables predicting a range of anxiety disorders.

The purpose of the current study was to identify early life predictors of anxiety across childhood and early adolescence, in a sample of at-risk children. It was hypothesised that family environment variables (maternal overinolvement, maternal negativity, attachment insecurity, maternal anxiety) observed at age 4 would be significantly and positively associated with increased youth anxiety disorders and symptoms across the four assessment points: baseline, 2-year, 5-year, and 8-year follow-up. Although our previous research with this sample identified these as additive predictors, that is, these environments increased risk for all children, we also explored the theorised notion (supported in other empirical research, e.g., Lewis-Morrarty et al., 2012; Lewis-Morrarty et al., 2015) that the familial environment variables would moderate the relationship between BI and anxiety across the four time points. Specifically, we hypothesised that BI children with higher maternal overinvolvement, higher maternal negativity, attachment insecurity and higher maternal anxiety would experience more anxiety in early adolescence. By identifying these early life predictors, prevention programs can be further tailored to reduce a child's risk for the development of anxiety disorders across childhood and early adolescence.

\section{Method}

This study is an 8-year follow-up of a sample of behaviorally inhibited (BI) and behaviorally uninhibited (BUI) preschool children and their parents. A detailed description of the sample, measures and assessments conducted at baseline, 2- and 5-year assessments can be found in our earlier papers (Hudson, Dodd, \& Bovopoulos, 2011; Hudson \& Dodd, 2012; Hudson et al., 2011).

\section{Participants}

At baseline, 102 BI and 100 BUI children aged between 3 years 2 months and 4 years 5 months $(M=4$ years, $\mathrm{SD}=4$ months $)$ participated in assessments. Of these, $72.8 \%$ participated in the 8-year follow-up (61 BI and $86 \mathrm{BUI})$. The mean time between baseline assessment and 8-year 
follow-up was 7 years 10 months $(\mathrm{SD}=4.9$ months). Participants were initially recruited through local preschools and via an advertisement in a free parenting magazine. Initial BI classification was made at baseline on the basis of mothers' report using the Short Temperament Scale for Children (STSC), described below. Children scoring more than one standard deviation above or less than one standard deviation below the normative mean on the Approach Scale were classified as BI or BUI respectively. For families participating in the 8-year follow-up $(n=147)$, there were no significant differences between BI groups on age, sex, family income, maternal age, family structure (See Table 1). The BI group was significantly more likely to classify themselves as being of Asian ethnicity than the BUI group (compared to other ethnic categories), $\chi^{2}(5, \mathrm{~N}=127)=12.39, \mathrm{p}=.03$.

\section{Measures}

Behavioral Inhibition (BI). BI was assessed at baseline using the approach scale of STSC, a parent-report measure containing 30 items. The STSC has adequate validity, good internal consistency and reliability (Sanson, Prior, Garino, Oberklaid, \& Sewell, 1987). The internal consistency for the approach scale in the present sample at baseline was $\alpha=.92$.

BI was also assessed at baseline using observed laboratory tasks similar to those used by Kagan and colleagues (Garcia-Coll, et al., 1984). Children's responses to a new room, novel toy, masked experimenter dressed in a strange suit and a same-sex unfamiliar peer were observed. Behaviors used to determine inhibition status included: i) time spent proximal to the mother; ii) amount of time starting at the peer; iii) time spent talking; iv) number of approaches to the stranger; and v) number of approaches to the peer. A participant was defined as BI based on observation if they scored above a pre-determined cut-off on three or more of these five behaviors (Rapee, Kennedy, Ingram, Edwards, \& Sweeney, 2005). Inter-rater reliability for observed BI was determined by having a second trained coder independently score the videotapes for $25 \%$ of the baseline sample. The inter-rater reliability for number of cutoffs exceeded was ICC $=.91$, and for overall BI classification was kappa $=.79$. 
Maternal anxiety disorders. At baseline, mothers were interviewed with the Anxiety Disorders Interview Schedule for DSM-IV (DiNardo \& Barlow, 1990) to assess current and past diagnoses. These were combined to give a measure of the number of anxiety disorders mothers had met criteria for in their lifetime, to capture anxiety severity as well as clinical status. Diagnoses were assigned by trained clinicians unaware of the child's group and anxiety status. A total of 20 cases $(10 \%)$ were coded by a second clinician from videotape. Interrater agreement for the number of lifetime anxiety diagnoses was high $(\mathrm{ICC}=.91)$.

Maternal Overinvolvement and Negativity. Maternal overinvolvement and negativity were assessed at baseline using a speech preparation task and the Five-Minute Speech Sample (FMSS). Additionally, overinvolvement was assessed using the Parent Protection Scale (PPS). Each of these measures is described briefly below. Further details are provided in our earlier paper (Hudson, Dodd, \& Bovopoulos, 2011). After converting the data from these measures to z-scores, means were calculated to construct a single overinvolvement variable and a single negativity variable. Overinvolvement during the speech preparation task was significantly correlated with Emotional Over-Involvement on the FMSS (EOI; $r=.178, p<.05)$ and the PPS $(r=.151, p<.05)$. EOI was also significantly correlated with the PPS $(\mathrm{r}=.174, \mathrm{p}<.05)$. The negativity scale was made up of criticism on the FMSS and warmth during the speech preparation task. These measures were not significantly correlated $(\mathrm{r}=-.054, \mathrm{p}>.05)$.

Parent Protection Scale. The PPS was used to assess maternal behaviors related to overprotection and autonomy granting at baseline (Thomasgard, Metz, Edelbrock, \& Shonkoff, 1995). The PPS contains 25 items (on a scale 0-3) and four subscales: Supervision, Separation, Dependence and Control. The Control scale was of interest to the current study and includes items such as 'I determine who my child will play with' and 'I dress my child even if he/she can do it alone'. The PPS has adequate internal reliability, re-test reliability, criterion and content validity (Thomasgard \& Metz, 1999; Thomasgard, et al., 1995). The internal consistency was $\alpha=.65$. 
Speech preparation task. At baseline, mothers were observed interacting with their child during a three-minute speech preparation task adapted from Hudson and Rapee (2001). The tasks were videotaped and maternal involvement and maternal negativity were coded by two postgraduate students in psychology, trained in the coding system. Both coders were unaware of participants' diagnostic status and rated each interaction. The reliability for the average of these ratings at baseline was ICC $=.94$ for the overinvolvement factor and ICC $=.73$ for the negativity factor.

Five Minute Speech Sample. The FMSS was conducted and coded according to the method described by Magana and colleagues (Magana et al., 1986). At baseline, parents were asked to talk about their child and their relationship uninterrupted for 5 minutes. The speech samples were videotaped, transcribed and coded for criticism and over-involvement as outlined in the coding manual (Magana, et al., 1986). Coders were unaware of participants' diagnostic status or group membership. A subset of 48 (24\%) transcripts were assessed for inter-rater reliability at baseline: Overinvolvement $(\mathrm{kappa}=.63)$, Criticism $(\mathrm{kappa}=.96)$.

Attachment. At baseline, child-mother attachment was assessed using the preschool version of the Strange Situation procedure (Cassidy, Marvin, \& Group, 1992). Children were classified as having secure, insecure-avoidant, insecure-ambivalent, disorganised-controlling or insecure-other attachment following coding of videotaped interactions by one of two certified coders trained in the Cassidy-Marvin (Macarthur) Preschool Attachment Classification System. Insecure-other was combined with disorganised for the analyses. Both coders independently coded $42(21 \%)$ cases and reliability for classification was kappa $=.72$.

Child Anxiety Disorders. Child anxiety diagnoses were assessed at baseline, 2-year, 5-year and 8-year follow-up using the Anxiety Disorders Interview Schedule for DSM-IV, parent/child version (ADIS-P-IV) (Silverman \& Nelles, 1988). At baseline and 2-year follow-up, only the parent was interviewed. At 5-year and 8 -year follow-up both the parent and child were interviewed and composite diagnoses were assigned taking both responses into consideration, that is, a diagnosis 
was given if either parent OR child provided information that the symptoms were present at a clinical level. Diagnoses and Clinical Severity Ratings (CSRs on a scale of 0-8) were assigned by trained clinicians unaware of the child's group membership. Diagnoses were only considered 'clinical' if the CSR was 4 or greater. To assess reliability, $20 \%$ of the interviews were coded by a second clinician. Interrater agreement was as follows: presence of clinical anxiety diagnosis (baseline kappa $=.86,2$-year follow-up kappa $=.80,5$-year follow-up kappa $=.85,8$-year $=1.0$ ) In the current study, anxiety disorders were defined as the presence or absence of a diagnosis.

Child Anxiety Symptoms. Parent-reported symptoms of child anxiety were measured across the four assessment points using either the Preschool Anxiety Scale (PAS: baseline and 2year follow-up)(Spence, Rapee, McDonald, \& Ingram, 2001) or the Spence Children's Anxiety Scale (SCAS: 5-year and 8-year follow-up)(Spence, 1998) depending on the time point. The SCAS comprises 38 items and the PAS 28 items, each on a four-point scale (never, sometimes, often, always) assessing overall anxiety as well as specific aspects of anxiety (e.g., social anxiety, generalized anxiety, separation anxiety, obsessive-compulsive, physical injury fears, panic/agoraphobia). To allow comparisons over time, the raw scores were converted to z-scores according to available normative data. For the PAS, the z-scores were based on published normative data for 3 (baseline) and 5 year olds (2 year follow-up)(Spence et al., 2001). For the SCAS-P, the zscores were based on age and gender means published online (https://www.scaswebsite.com).

\section{Procedures}

Macquarie University Human Ethics Committee approved the study. Following the initial screen using the STSC, children meeting entry criteria were invited to take part in the full study and mothers provided written informed consent. At baseline and follow-up assessments, participants visited the university for approximately 2 -hour sessions. In the follow-up assessments, child anxiety diagnoses were assessed and various other tasks, not reported here, were completed. Questionnaire measures were typically completed prior to the assessment either in hard copy or online. After each assessment, participants were rewarded with $\$ 50$ and a small gift for the child. 


\section{Analysis plan}

There were two dependent variables for anxiety: anxiety symptoms and presence of an anxiety diagnosis. Analyses for these DVs are conducted and reported separately. In addition, there were a number of predictor variables: BI group and 4 family environment variables including number of lifetime (current and past) maternal anxiety diagnosis; maternal over-involvement; maternal negativity; and mother-child attachment security (2 levels: secure vs insecure).

For the anxiety symptoms, we first conducted latent growth curve modelling (LGM) to examine predictors of change in scores over the four time-points using mixed-effects modelling. This was done using $R$ ( $R$ Core Team, 2013) with lmer() function from the lme4 package (Bates, Maechler, Bolker, \& Walker, 2014) in combination with lmerTest package (Kuznetsova, Brockhoff \& Bojesen, 2014). We first ran an initial LGM model that included the linear and quadratic effects of time as fixed predictors of anxiety symptom z-scores and their corresponding randomparticipants effects (random intercepts for participants and random slopes for linear and quadratic effects of time varying by participant). ${ }^{1}$ Time was anchored such that zero represented the initial assessment point (Biesanz, Deeb-Sossa, Papadakis, Bollen, \& Curran, 2004). The model included BI group $(0=\mathrm{BUI} ; 1=\mathrm{BI})$ and its interaction with the linear and quadratic effects of time to model different growth curves between groups. Given differences in ethnicity between BI groups at baseline and follow-up, we also included Asian ethnicity $(0=$ No; $1=$ Yes $)$ as a control variable.

Next, we ran four LGM models that separately assessed family environment variables: the number of lifetime maternal anxiety diagnoses at baseline; maternal over-involvement; maternal negativity; and mother-child attachment security. These models examined whether (and how) these variables can explain the individual differences in the growth curves. Each variable was added to the initial model above, starting with main effects and then adding higher order interactions with BI

\footnotetext{
${ }^{1}$ We also explored the models that omitted the random and/or quadratic effect but the fit of these models was significantly worse than the reported model (log-likelihood ratio test, ps $<.05$ ), indicating the importance of incorporating these effects in the LGM to account for growth curves.
} 
group, linear and quadratic effects of time. To ensure sufficient power and avoid multi-collinearity, we ran this model separately for each family environment variable. This means that, for each model, BI group, a family environmental variable (e.g., the number of lifetime maternal anxiety diagnoses), and their interactions were included as fixed effect predictors.

For the anxiety diagnosis, we also attempted to apply a series of similar latent growth curve models using the four time-points to mirror the analyses for anxiety symptoms. However, because this variable is dichotomous and requires non-normal linking functions, the models consistently produced convergence errors. We therefore decided to run logistic regressions with anxiety diagnosis at 8-year follow-up as the dependent variable to be in keeping with the analyses reported in Hudson and Dodd (2012) for the 5-year follow-up of this sample.

Logistic regression analyses were conducted for anxiety diagnosis as a dependent variable using the base package in R. Each of the risk factors (BI group and the five family environment factors) was included in a separate analysis to ensure sufficient power and avoid multi-collinearity. First, analyses were conducted without the corresponding baseline measure of anxiety and subsequently ran again with baseline anxiety controlled for. We also included Asian ethnicity as a controlling variable in all analyses. To examine the interplay between BI and other risk factors, four additional logistic regressions were conducted. These included a main effect of BI group and its interaction with family environment variables. Therefore, these models assess whether each family environment variable predicts anxiety at follow-up after controlling for BI group, as well as any interactions between BI group and family environment variables ${ }^{2}$.

All reported analyses were conducted with BI group according to parent report as participants were initially recruited on this basis. To examine whether the pattern of results was consistent with the reduced sample of participants whose parent report BI grouping matched their

\footnotetext{
${ }^{2}$ To examine the effect of sex, we included sex in the above models, and also the interaction between BI and sex. Neither Sex nor the interaction between BI and sex were significant and did not change the outcome of the models.
} 
observed BI group allocation, all analyses were conducted again. There were some minor differences in statistical significance between the original analyses and these analyses, likely to due to reduced power, but the overall pattern of results was the same. Results from the analyses conducted with the reduced sample are provided, and discrepancies in statistical significance are highlighted, in Supplementary Tables S1 and S2.

\section{Results}

Descriptive statistics for all three anxiety dependent variables at each time point are shown in Table 2. Table 3 provides the descriptive details maternal anxiety disorders, maternal over-involvement, maternal negativity, and mother-child attachment security at baseline.

\section{Missing data}

The following percentages indicate the amount of missing data for anxiety diagnoses across the 4 time points for BI children: $0 \%$ (baseline); $15 \%$ (2-year); 30\% (5-year); $40 \%$ (8-year); and, BUI children: 0\% (baseline); 9\% (2-year); 11\% (5-year); 14\% (8-year). The following percentages indicate the amount of missing data for anxiety symptoms across the 4 time points for BI children: 3\% (baseline); 16\% (2-year); 34\% (5-year); 43\% (8-year); and, BUI children: 1\% (baseline); 6\% (2year); $9 \%$ (5-year); $25 \%$ (8-year). Data were missing either because the family could not be contacted or because they chose not to participate at follow-up.

To deal with missing data, we took two strategies. For the latent growth curve modelling, we used a maximum likelihood method to estimate parameters. This method requires that data are missing at random. For data to be considered missing at random missingness can be conditional on other variables included in the analyses but cannot depend on the values of variables that are missing. Thus, the fact that missing data can be predicted by BI group, which is also measured and included in the analyses means that the data can be considered missing at random (MAR). As Marsh et al. (in press) argued, in a longitudinal panel design, this assumption is unlikely to be seriously violated because, even if missingness is dependent on the variable itself, this dependency 
is likely to be accounted for by the same variable assessed at a different time point. For the logistic regression, we used multiple imputation to deal with missing data and pooled results from five imputations are reported. MI was conducted following Enders (2010) using the mice package in R (van Buuren \& Griithuis-Oudshoorn, 2011). This method also rests on the MAR assumption as outlined above.

\section{Anxiety across time}

Figure 1a and $1 \mathrm{~b}$ show the correlations between anxiety across the four time-points. As expected the strength of the associations decreases as the time between assessments increases.

\section{Predicting Anxiety symptoms}

The results of the growth curve analysis are summarized in Table 4 . Figure 2 presents the predicted growth curve of anxiety scores for the BI and BUI groups. As expected, BI group positively predicted the intercept (beta $=0.94, p<.01$ ), indicating that the BI group had higher anxiety scores at age 4 (as reported in Hudson et al., 2011). In addition, there was a significant interaction between the linear effect of time and BI group (beta $=-0.13, p<.01$ ), this suggests that the initial linear trend of anxiety scores differ across the groups; whereas the BUI group initially exhibited an increase in anxiety, the BI group showed an initial decrease in anxiety.

Maternal anxiety. Table 4 reports the results for the model examining maternal anxiety. The number of current and past maternal anxiety diagnoses at baseline was a significant predictor of the initial level of anxiety symptom scores $($ beta $=.23, p<.01)$, with a greater number of maternal anxiety diagnoses associated with higher child anxiety at baseline (as reported elsewhere, Hudson et al., 2011). The three-way interaction with linear time and BI group was significant (beta $=0.05, p<$ $.05)$ but the effect size was small. Figure 3 shows this interaction. Scrutiny of the plot suggests that the interaction is subtle and is overshadowed by large main effects of BI and maternal anxiety. 
Maternal Overinvolvement and Negativity. The results for maternal parenting are also shown in Table 4. Maternal over-involvement at baseline significantly interacted with BI group to explain the linear $($ beta $=0.14, p<.01)$ and quadratic $($ beta $=-0.02, p<.05)$ slopes for time. Maternal over-involvement also had a main effect on the linear slopes for time (beta $=0.11, p<$ .05). To interpret these multiple interaction effects, we plotted the predicted growth curve of children with high- and low- maternal over-involvement for both BI and BUI groups. Figure 4 suggests that maternal overinvolvement does not impact anxiety trajectory for BUI children but does affect anxiety in BI children over time. Although maternal overinvolvement was not associated with baseline child anxiety within the BI group, when mothers had low levels of overinvolvement, anxiety in the BI children rapidly declined such that by age 9 it resembled that of BUI children. In contrast, when mothers had high levels of overinvolvement, high anxiety levels in BI children declined less rapidly.

For maternal negativity, there was a significant positive association with initial anxiety scores $($ beta $=.29, p<.01)$ as reported elsewhere (Hudson et al., 2011); children whose mothers were more negative at baseline had high levels of anxiety at baseline. In addition, parental negativity significantly predicted the linear slopes (beta $=-0.12, p<.05)$. This indicates that children whose mothers were more negative at baseline had higher baseline anxiety (previously reported) and then for both $\mathrm{BI}$ and BUI groups, the slope value is more negative if negativity is high relative to when it is low. That is, children whose mothers were more negative at baseline had a steeper decrease in anxiety over time than those whose mothers were less negative. This must be interpreted in the context of the children with more negative mothers having higher baseline anxiety scores. Interactions with BI were not significant.

Attachment Security. The results for attachment security are shown in Table 4. As can be seen, attachment security did not show any significant effects in the LGM analysis.

\section{Predicting presence of an anxiety diagnosis}


Table 2 provides the descriptive data for anxiety disorders across the four time points. Frequency of specific anxiety disorders at 4, 6 and 9 have been reported elsewhere and hence we provide specific anxiety disorders at age 12 . BI children were more likely than BUI children to have social anxiety disorder (BI: 26.2\%; BUI: $\left.5.8 \%, \chi^{2}(1, \mathrm{~N}=147)=12.15, p<.001\right)$ and OCD (BI: 4.9\% BUI: $0 \% \chi^{2}(1, \mathrm{~N}=147)=4.32, p=.04$. There was a non-significant trend for BI children to be more likely to have SAD (BI: 3.3; BUI: $\left.0 \%, \chi^{2}(1, \mathrm{~N}=147)=2.86, p<.1\right)$. There were no significant differences between BI and BUI children in the prevalence of GAD (BI: 13.1\%; BUI: 5.8\%), Specific Phobia (BI: 11.5\%; BUI: 9.3\%) or Panic Disorder (BI: 1.6\%; BUI: $0 \%$; $p \mathrm{~s}>.05$ ).

Table 5 summarizes the results of the logistic regression predicting the presence of an anxiety diagnoses at age 12 . Number of maternal lifetime anxiety disorders, and maternal overinvolvement predicted the presence of an anxiety diagnosis at follow-up, even after controlling for baseline anxiety. For analyses that included BI together with each family environment factor and their interaction, none of the interaction terms were significant $(p s>.05)$. Given the absence of significant interaction effects, we re-ran the models after eliminating the interaction effects but keeping BI in the models. The obtained results are reported in Table 5. BI, maternal anxiety and overinvolvement all significantly predicted the presence of anxiety diagnosis at age 12 . After controlling for anxiety and BI at baseline, only number of maternal lifetime anxiety disorders remained significant. Maternal negativity and attachment did not predict anxiety at follow-up, regardless of whether baseline anxiety was controlled for.

\section{Discussion}

This eight-year longitudinal study examined early life predictors of anxiety disorders in early adolescence. The study utilized observational techniques and questionnaires to assess familial and temperamental variables, as well as both structured diagnostic interviews and questionnaires to examine the presence of anxiety. This study extends the previous literature by uniquely assessing multiple family environment factors to predict early adolescent anxiety including maternal anxiety, 
maternal negativity, maternal overinvolvement and mother-child attachment. Consistent with earlier studies, preschool children were more likely to experience anxiety symptoms and disorders in early adolescence when the child was inhibited, when there was a history of maternal anxiety disorders and when mothers displayed high levels of overinvolvement. These findings held even after accounting for baseline symptoms. Further, this study identified a moderation effect between temperament and maternal behavior. That is, preschool children with an inhibited temperament were at risk for increased anxiety symptoms in early adolescence when their mothers displayed high over-involvement. Inhibited children whose mothers were not overinvolved during the preschool years showed similar anxiety levels in adolescence to uninhibited peers. Although this interaction effect was not observed when anxiety disorder status was measured, maternal overinvolvement remained a significant predictor of child anxiety disorder status.

These findings are consistent with the large body of literature that consistently identifies an association between parental overinvolvement and anxiety symptoms (McLeod, Wood, \& Weisz, 2007; van der Bruggen, Stams, \& Bogels, 2008). The current study extends the existing literature as it highlights the moderating role parenting plays in shaping the development of anxiety symptoms in inhibited children. Previous longitudinal studies have identified a moderating relationship between inhibition and maternal control specifically for social anxiety symptoms (Lewis-Morrarty et al., 2012). Importantly, the current study shows that this relationship may be present for total anxiety symptoms and holds even after controlling for baseline anxiety symptoms. This finding is also consistent with theoretical models that highlight the importance of restrictive and overprotective parenting in reducing the child's opportunities for exposure to novelty or potentially difficult situations (Hudson \& Rapee, 2004; Ollendick \& Grills, 2016). Providing too much involvement in an inhibited child's activities therefore further reduces opportunities for the child to discover accurate data about threat and coping, increasing the child's vulnerability to anxiety.

Consistent with our earlier findings, a history of maternal anxiety was identified as a significant additive predictor of child anxiety symptoms and disorders, such that children whose 
mothers had an anxiety disorder were more likely to experience higher anxiety symptoms and disorders over time. This effect of maternal anxiety was robust across all analyses. The results indicate that this is primarily a main effect of maternal anxiety such that BUI and BI children who have an anxious mother are at similarly increased risk for anxiety over time. There was a significant three-way interaction between maternal lifetime diagnoses, BI and the linear effect of time but the effect size was small and there is little evidence from the plot (Figure 3) that this interaction is meaningful. It is possible that BI children whose mothers were anxious had a slightly shallower decline in their slope across time than BI children whose mothers were not anxious but this is a very subtle effect and should be interpreted with caution. The results provide strong support for the important role maternal anxiety plays in affecting child anxiety over time.

Parenting high in negativity was associated with increased anxiety symptoms at baseline (as reported earlier; Hudson et al., 2011), followed by a decline in symptoms over time such that by age 12, early maternal negativity had little effect on anxiety symptoms. Maternal negativity did not interact with BI indicating that the effects of negativity are consistent for both inhibited and uninhibited children. Maternal negativity also did not predict disorder status in early adolescence. Taken together there is little evidence that maternal negativity at age 4 significantly affects anxiety risk through to early adolescence. With this in mind, the positive association between high negativity and anxiety symptoms found at baseline may have been due to mothers responding negatively to their child's anxiety rather than maternal negativity playing a causal role in their child's anxiety. These findings are in keeping with previous work showing that parental warmth and rejection are weakly and inconsistently associated with anxiety disorders (McLeod et al., 2007). Perhaps the inconsistent finding in the current study is a result of the sample size not being sufficiently large to detect such small effects.

Mother-child attachment security did not significantly predict anxiety symptoms or disorders over time. Although this is consistent with results from earlier assessments utilizing this sample (Hudson \& Dodd, 2012), the finding conflicts with a recent study showing inhibited 
children with an insecure mother-child attachment were at increased risk of adolescent social anxiety symptoms (Lewis-Morrarty et al., 2015). Specifically, Lewis-Morrarty and colleagues found that infant inhibited males with an insecure-resistant attachment were at increased risk of adolescent social anxiety. In the current study, we only identified 12 children in the insecure ambivalent category and thus we had to collapse across types of insecurity. It therefore remains possible that children who have an ambivalent attachment may be at increased risk for anxiety disorders. We also assessed attachment at age 4 whereas Lewis-Morrarty and colleagues assessed attachment much earlier (14 months), which may explain some of the inconsistency in findings.

Perhaps most surprising was the limited value of early anxiety as a predictor of anxiety disorders in early adolescence. Previous research has demonstrated that high anxiety is relatively stable over time, yet stability rates of disorders have been shown to vary dramatically between studies (Weems, 2008). In previous longitudinal assessments of this sample, anxiety disorders in early childhood predicted anxiety disorders during middle childhood. Our current analysis showed continuity in anxiety symptoms and disorder over the short term but anxiety disorders at age 4 were not significantly related to anxiety disorders at age 12 . One possible explanation for the absence of a significant effect from preschool to pre-adolescence here is the greater attrition in the inhibited sample at this follow-up, with only $60 \%$ of the sample participating compared to $86 \%$ of the uninhibited sample. This significantly reduced the number of children with anxiety disorders in the final sample. The finding should therefore be interpreted with some caution.

As expected, BI at age 4 was a significant predictor of anxiety across time and this was relatively robust across outcome measures. The comparisons by individual anxiety diagnosis indicate that whilst BI children are significantly more likely to meet criteria for an anxiety diagnosis at age 12 , this is primarily driven by an increase in social anxiety disorder diagnoses. Behaviorally inhibited preschool children were also at greater risk of developing OCD by early adolescence and a non-significant trend was observed for separation anxiety disorder. In our previous work with this sample we have shown that BI predicts not only social anxiety disorder but also separation anxiety 
disorder and generalised anxiety disorder (Hudson \& Dodd, 2012). The current findings indicate that BI is associated with a clear increased risk for social anxiety disorder (Clauss \& Blackford, 2012), but that this temperamental construct also places the child at risk for other anxiety related disorders. In this sample, early adolescence was a period of marked remission of anxiety disorders for inhibited children. Although high rates of anxiety disorders were observed in the inhibited sample during childhood (54-73\%), only $36 \%$ of inhibited pre-schoolers were highly anxious in early adolescence. This finding highlights that, although inhibition is a risk factor for anxiety disorders, many inhibited children, in fact the majority, do not experience long-term problems with mental health (Degnan \& Fox, 2007).

A clear strength of this study is the use of multiple assessment methods to assess the child's early family environment as well as assessment of anxiety symptoms and disorders over an 8-year period. A significant limitation of the study is the sole focus on maternal behaviours and the absence of critical data on the role of fathers. Recent data suggest that fathers also play a key role in the development of anxiety symptoms (Lazarus et al., 2016) and thus the exclusion of fathers significantly limits the conclusions that can be made about parenting in general. Another significant methodological and conceptual limitation is the extreme groups design, that ignores the 'typical' presentation of children. As is the case with much of the work examining the category of behavioural inhibition, the child who is neither eager to explore nor avoidant of exploration is not captured within this study design and thus we are unable to generalise these findings to typical children instead of children at either end of the inhibition spectrum. Further, although the sample included a range of ethnically diverse families, indicative of the Sydney population, the children are primarily from intact families with a moderate socio-economic advantage, thus limiting the generalisations of these findings to the broader population. The sample size across the four followup assessments also limited the study's capacity to examine all of the familial variables together. Although the analyses tell us the predictive power of each family environment variables in predicting anxiety over and above baseline symptoms and temperament, they are unable to 
determine the unique contribution of these variables over and above other family environment variables. Future research would benefit from examining the unique value of these variables as well as the potential moderation and mediation between family environment variables that may exist.

Despite these limitations, the results of this study present clear clinical implications for the prevention of anxiety disorders in children and early adolescents. Targeted interventions should be made available for families of children with an inhibited temperament and specifically, these interventions should empower mothers to encourage their child's independence and reduce high levels of overinvolvement. Interventions that specifically reduce this parenting behaviour in inhibited children will be important for reducing anxiety in the long term. These findings also make a strong case for the delivery of interventions to mothers who experience significant anxiety. Adult anxiety disorders are treatable and preventable (Craske et al., 2017; Hudson, 2017). Thus, the familial transmission of anxiety from parent to child can be partially prevented by providing evidence-based treatments to parents who experience anxiety disorders (Ginsburg et al., 2015). Such treatment can reduce the likelihood parents will provide their children with biased negative information about the world, or specific aspects of the world, and reduce the likelihood that they will model anxious and avoidant behaviors to their child. Targeting these key variables will likely reduce the prevalence of anxiety disorders in children and adolescents. 
Table 1.

Demographic Data at 8-year Follow-up Across Groups

\begin{tabular}{|c|c|c|}
\hline & $\mathrm{BI}$ & BUI \\
\hline Demographic & $N=61$ & $N=86$ \\
\hline Mean Age in years (SD) & $11.8(.48)$ & $11.8(.36)$ \\
\hline Mother's age in years (SD) & $44.98(4.61)$ & $44.39(4.56)$ \\
\hline Gender ( $\%$ female $)$ & 50.8 & 48.8 \\
\hline \multicolumn{3}{|l|}{ Family Structure (baseline) } \\
\hline$\%$ Two-parent & 91.8 & 88.4 \\
\hline \multicolumn{3}{|l|}{ Family Income } \\
\hline$\%>\$ 80,000$ & 75.5 & 71.4 \\
\hline$\% \$ 40-80,000$ & 18.9 & 17.1 \\
\hline$\% \$ 0-40,000$ & 5.7 & 11.4 \\
\hline \multicolumn{3}{|l|}{ Ethnicity } \\
\hline$\%$ Australian/Caucasian & 57.4 & 78.8 \\
\hline$\%$ Asian & 21.3 & 4.7 \\
\hline$\%$ European & 11.5 & 11.8 \\
\hline$\%$ American & 3.3 & 1.2 \\
\hline$\%$ African & 3.3 & 1.2 \\
\hline \%Middle Eastern & 3.3 & 2.4 \\
\hline
\end{tabular}


Table 2. Descriptive statistics for child anxiety variables across time.

\begin{tabular}{lccccccccc}
\hline & \multicolumn{2}{c}{ Age 4 } & \multicolumn{2}{c}{ Age 6 } & \multicolumn{2}{c}{ Age 9 } & \multicolumn{2}{c}{ Age 12 } \\
& BI & BUI & BI & BUI & BI & BUI & BI & BUI \\
& & & & & & & & \\
\hline $\begin{array}{l}\text { Parent reported child } \\
\text { anxiety (PAS/SCAS) }\end{array}$ & 1.08 & -0.83 & 1.32 & -.056 & 0.48 & -0.42 & -0.11 & -0.59 \\
$\begin{array}{l}\text { Z-scores M (SD) } \\
(1.24)\end{array}$ & $(0.73)$ & $(1.36)$ & $(0.84)$ & $(1.22)$ & $(0.71)$ & $(1.19)$ & $(0.76)$ \\
& & & & & & & & \\
$\begin{array}{l}\text { Presence of anxiety } \\
\text { diagnosis- total }\end{array}$ & 74 & 17 & 52 & 12 & 38 & 16 & 22 & 16 \\
number (\% of group) & $(73 \%)$ & $(17 \%)$ & $(60 \%)$ & $(12 \%)$ & $(54 \%)$ & $(18 \%)$ & $(36 \%)$ & $(19 \%)$
\end{tabular}

Notes: $\mathrm{BI}=$ behaviorally inhibited; BUI $=$ behaviorally uninhibited 
Table 3. Family environment variables by group for full sample at baseline.

\begin{tabular}{lcc}
\hline & BI & BUI \\
\hline Maternal lifetime anxiety & $\mathrm{n}=74$ & $\mathrm{n}=50$ \\
diagnosis at baseline & $(73 \%)$ & $(50 \%)$
\end{tabular}

$\begin{array}{lcc}\begin{array}{lcc}\text { Maternal overinvolvement } \\ \text { (z score) }\end{array} & 0.14 & -0.14 \\ & (0.70) & (0.59) \\ \text { Maternal negativity (z score) } & 0.13 & -0.16 \\ & (0.70) & (0.67)\end{array}$

Attachment security

$\begin{array}{lcc}\text { Secure } & \mathrm{n}=45 & \mathrm{n}=59 \\ & 45 \% & 60 \% \\ \text { Insecure } & \mathrm{n}=54 & \mathrm{n}=39 \\ & 55 \% & 40 \%\end{array}$

Note. Mean and (standard deviation) shown; for categorical variables the number of individuals in each category and (percentage) is provided. $\mathrm{BI}=$ behaviorally inhibited; $\mathrm{BUI}=$ behaviorally uninhibited 
Table 4.

Summary of the growth curve analysis on anxiety symptom scores

\begin{tabular}{|c|c|c|c|c|c|}
\hline & $\begin{array}{l}\text { No } \\
\text { baseline } \\
\text { predictors }\end{array}$ & $\begin{array}{l}\text { Maternal } \\
\text { lifetime } \\
\text { anxiety } \\
\text { diagnosis }\end{array}$ & $\begin{array}{l}\text { Maternal } \\
\text { over- } \\
\text { involvement }\end{array}$ & $\begin{array}{l}\text { Maternal } \\
\text { negativity }\end{array}$ & $\begin{array}{l}\text { Attachment } \\
\text { security }\end{array}$ \\
\hline Intercepts & $0.20 * *$ & -0.12 & $0.21 * *$ & $0.20 * *$ & $0.28 *$ \\
\hline BI group & $0.94 * *$ & $0.84 * *$ & $0.93 * *$ & $0.91 * *$ & $0.96 * *$ \\
\hline $\begin{array}{l}\text { Family } \\
\text { environment }\end{array}$ & & $0.23 * *$ & 0.09 & $0.29 * *$ & -0.16 \\
\hline $\begin{array}{l}\text { Family } \\
\text { Environment x } \\
\text { BI group }\end{array}$ & & 0.02 & 0.06 & 0.11 & -0.06 \\
\hline Ethnicity & 0.00 & 0.19 & -0.14 & 0.01 & -0.00 \\
\hline $\begin{array}{l}\text { Linear effects } \\
\text { for time }\end{array}$ & $0.17 * *$ & $0.13 * *$ & $0.15 * *$ & $0.16^{* *}$ & $0.13 * *$ \\
\hline $\begin{array}{l}\text { x BI group } \\
\text { x Family } \\
\text { environment }\end{array}$ & $-0.13 * *$ & $\begin{array}{l}-0.19 * * \\
0.02\end{array}$ & $\begin{array}{l}-0.15^{* *} \\
0.11 *\end{array}$ & $\begin{array}{l}-0.11 * * \\
-0.12 *\end{array}$ & $\begin{array}{l}-0.11^{*} \\
0.05\end{array}$ \\
\hline $\begin{array}{l}\text { x Family } \\
\text { environment x } \\
\text { BI group }\end{array}$ & & $0.05 *$ & $0.14 * *$ & -0.00 & -0.05 \\
\hline $\begin{array}{l}\text { Quadratic } \\
\text { effects for time }\end{array}$ & $-0.03 * *$ & $-0.03 * *$ & $-0.03 * *$ & $-0.03 * *$ & $-0.03 * *$ \\
\hline $\begin{array}{l}\text { x BI group } \\
\text { x Family } \\
\text { environment }\end{array}$ & 0.01 & $\begin{array}{l}0.01^{*} \\
-0.00\end{array}$ & $\begin{array}{l}0.01 \\
-0.01\end{array}$ & $\begin{array}{l}0.00 \\
0.01\end{array}$ & $\begin{array}{l}0.00 \\
-0.01\end{array}$ \\
\hline $\begin{array}{l}\text { x Family } \\
\text { environment x } \\
\text { BI group }\end{array}$ & & -0.00 & $-0.02 * *$ & -0.00 & 0.00 \\
\hline Intercepts & 0.62 & 0.59 & 0.73 & 0.66 & 0.70 \\
\hline $\begin{array}{l}\text { Linear slope for } \\
\text { time }\end{array}$ & 0.02 & 0.02 & 0.02 & 0.02 & 0.02 \\
\hline $\begin{array}{l}\text { Quadratic slope } \\
\text { for time }\end{array}$ & 0.00 & 0.00 & 0.00 & 0.00 & 0.00 \\
\hline
\end{tabular}

Notes: Each column represents a single model, with a different family environment factor included as a predictor. The baseline growth curve model (the leftmost column) includes the intercepts, linear slopes for time, and quadratic slopes for time with their respective random effects. Asian ethnicity was also added as a control variable. The rest of the models included the BI group, one family environment factor, and their interactions with the linear and quadratic effects for time. $*<.05, * *<.01$ 
Table 5.

Results of logistic regressions to assess the effect of each risk factor on the presence of an anxiety diagnosis at 8-year follow-up (results based on Multiple Imputation to handle missing data). Parent report BI groups.

\begin{tabular}{llll}
\hline & $\begin{array}{l}\text { Before controlling } \\
\text { for baseline anxiety }\end{array}$ & $\begin{array}{l}\text { After controlling for } \\
\text { baseline anxiety }\end{array}$ & $\begin{array}{l}\text { After controlling for } \\
\text { baseline anxiety and } \\
\text { BI group }\end{array}$ \\
\cline { 2 - 4 } $\begin{array}{l}\text { Behavioral } \\
\begin{array}{l}\text { Inhibition } \\
\text { Number of maternal }\end{array}\end{array}$ & $0.96^{*}$ & $1.00^{*}$ & \\
$\begin{array}{l}\text { lifetime anxiety } \\
\text { disorders }\end{array}$ & $0.49^{*}$ & $0.51^{*}$ \\
$\begin{array}{l}\text { Over-involvement } \\
\text { Negativity }\end{array}$ & $0.56^{*}$ & & \\
Attachment security & -0.12 & $0.49^{*}$ & 0.37 \\
\hline Note. & & & \\
& -0.14 & 0.04 & -0.04 \\
\end{tabular}




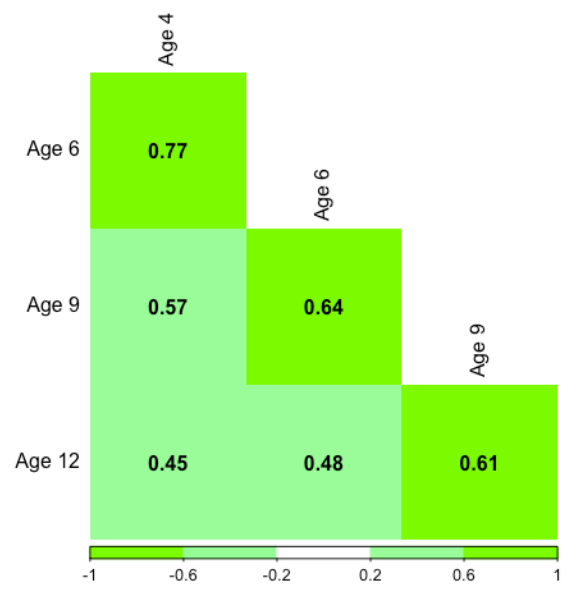

b

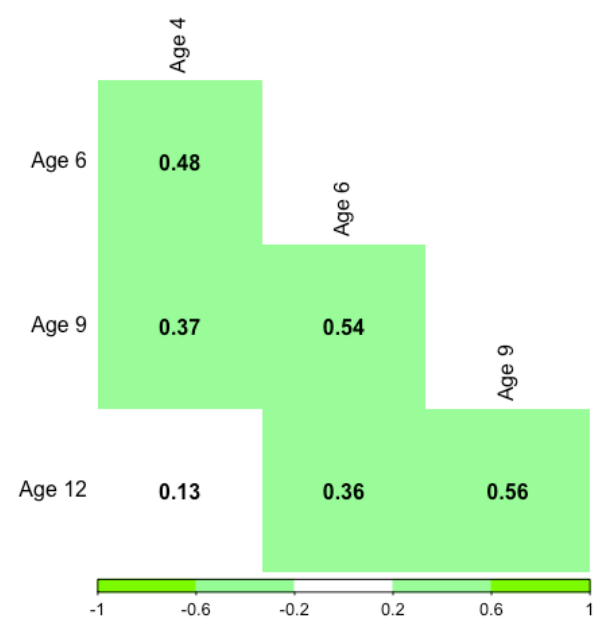

Figure 1. Correlation matrices showing continuity in anxiety over time. a shows anxiety symptom z-scores, b shows kappa for presence of an anxiety diagnosis. Cells in green are significant $p<0.001$, cells in white are not significant $p>.05$. Colour bar indicates strength of the coefficient. 


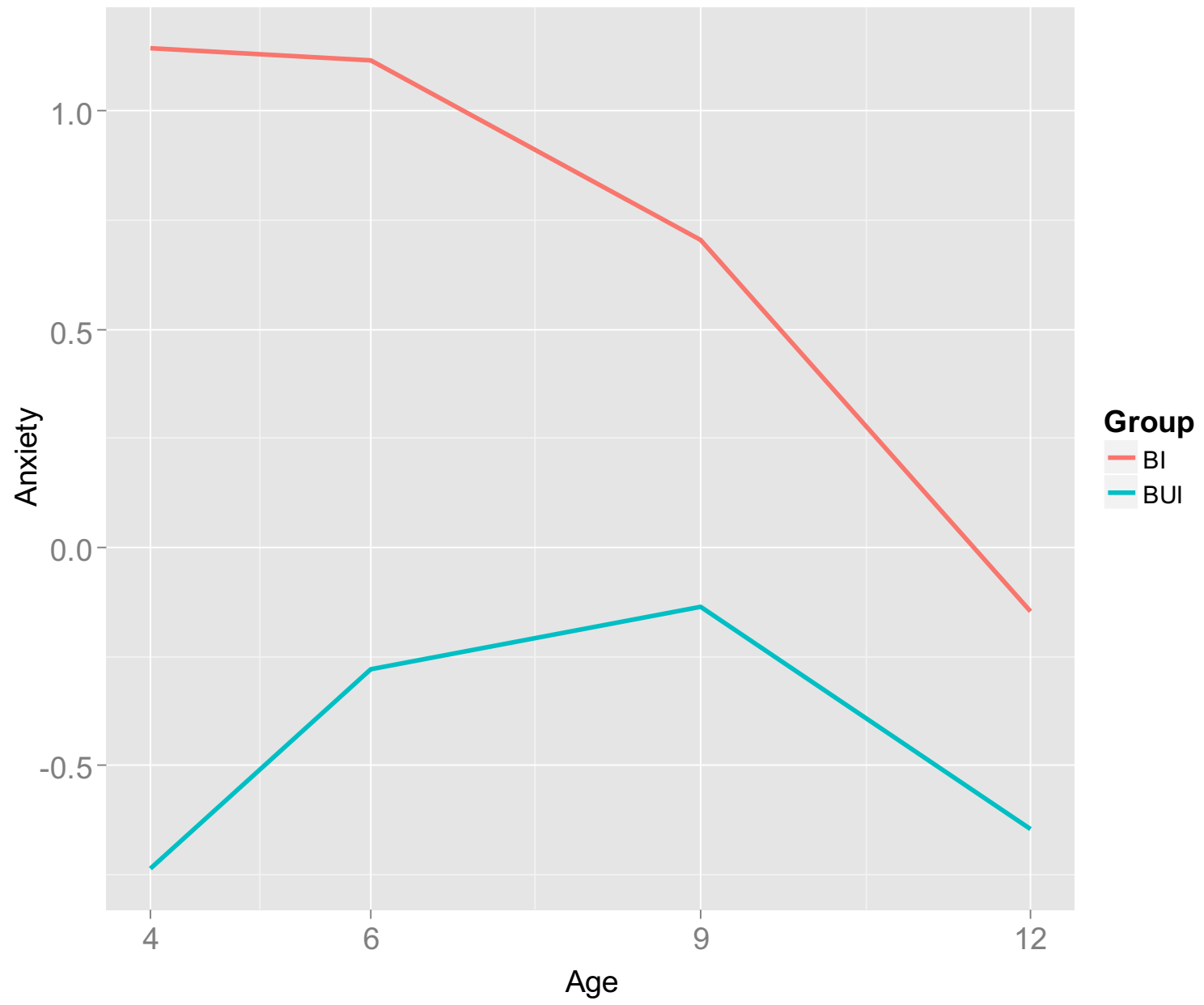

Figure 2: Predicted growth curve for anxiety symptoms of the behaviorally inhibited (BI) and uninhibited (BUI) children. 


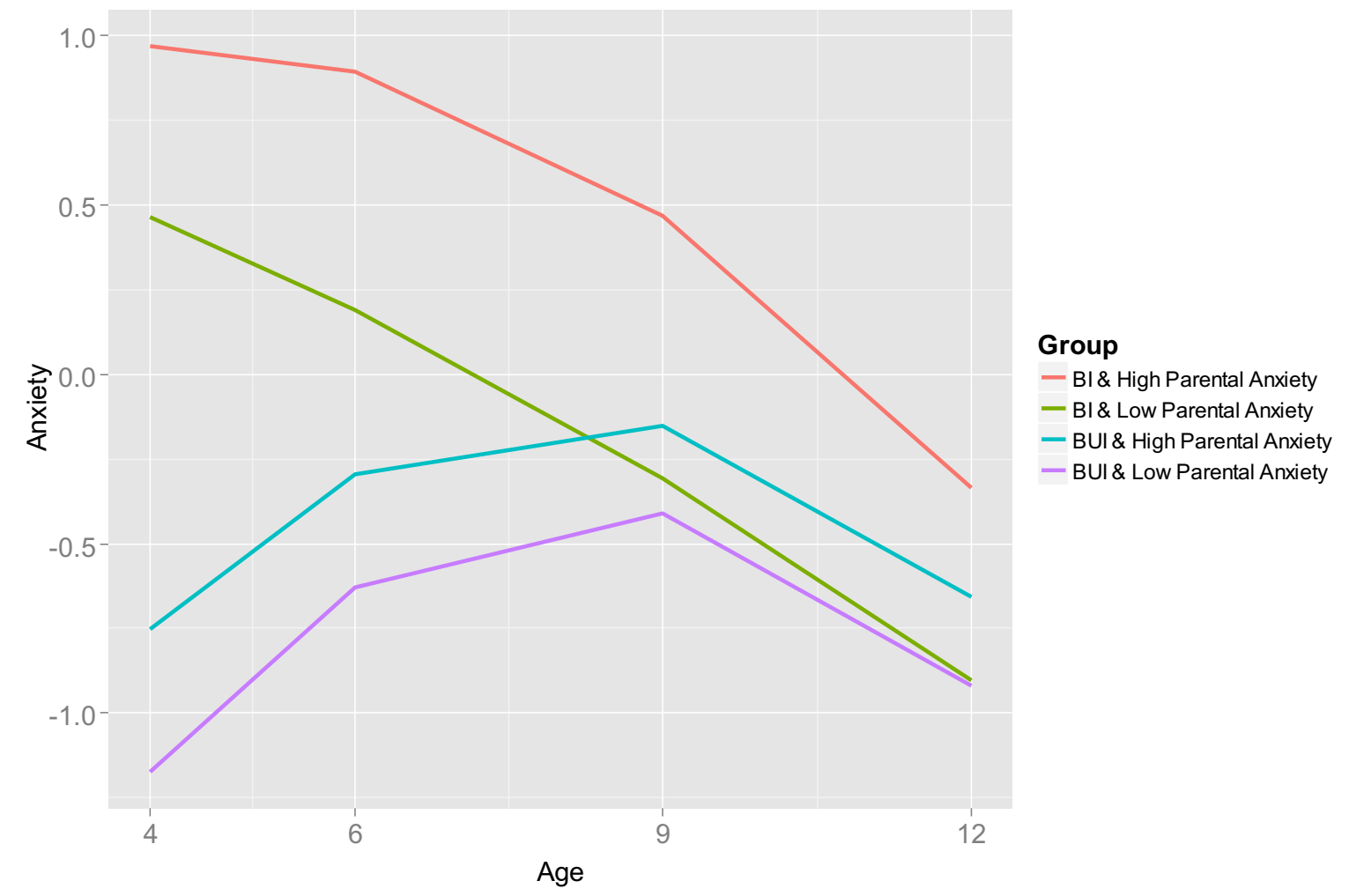

Figure 3: Predicted growth curve for anxiety symptoms across time for the BI and BUI children with high vs low maternal current and past anxiety. 


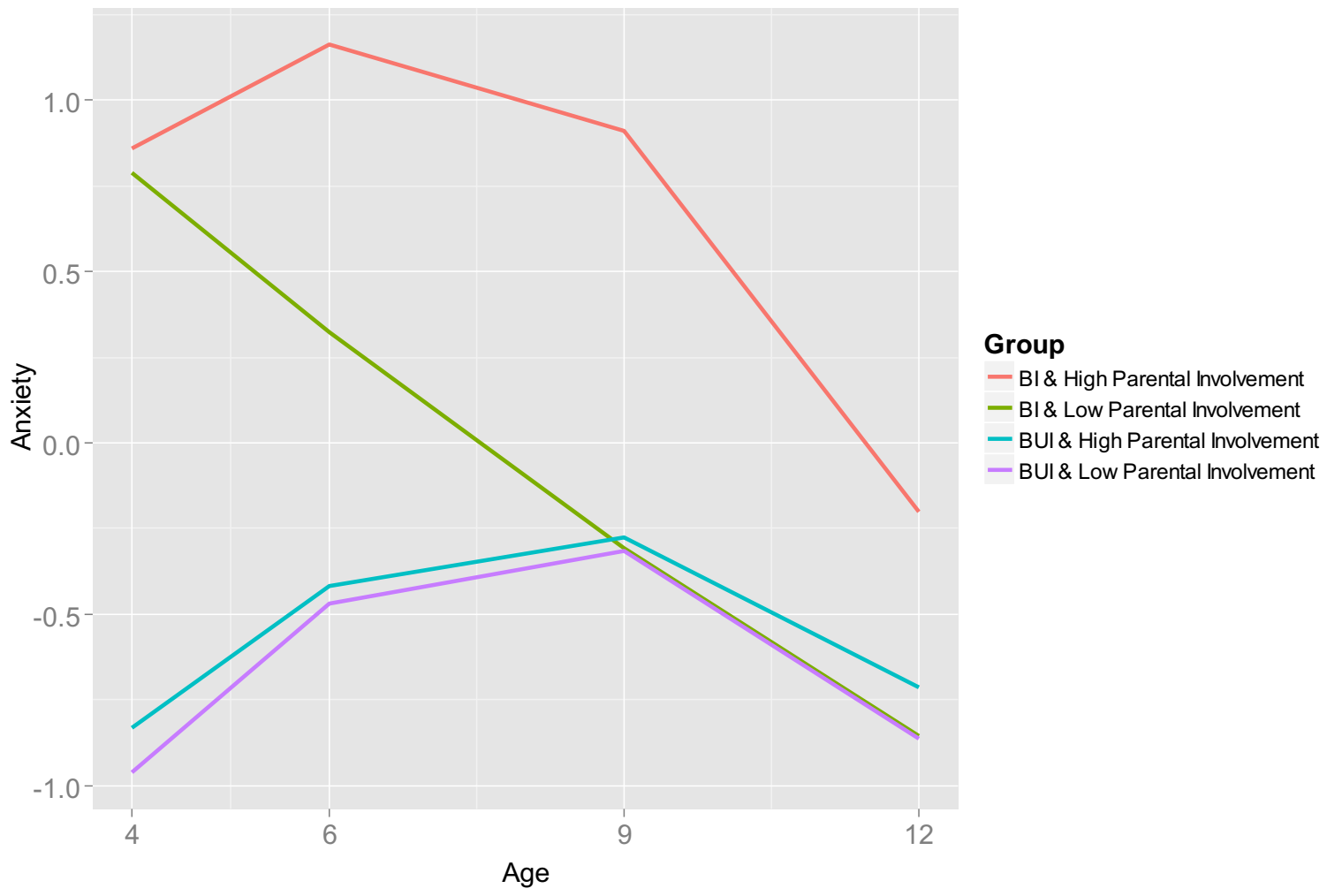

Figure 4: Parental over-involvement and anxiety symptom scores over time and BI group 


\section{References}

Ainsworth, M.D.S., Blehar, M.C., Waters, E., \& Wall, S.N. (2015). Patterns of attachment: A psychological study of the strange situation: Psychology Press.

Asbrand, J., Hudson, J.L., Schmitz, J., \& Tuschen-Caffier, B. (2017). Maternal Parenting and Child Behaviour: An Observational Study of Childhood Social Anxiety Disorder. Cognitive Therapy and Research, 41(4), 562-575. doi:10.1007/s10608-016-9828-3

Bates, D., Maechler, M., Bolker, B., \& Walker, S. (2014). lme4: Linear mixed-effects models using Eigen and S4. R package version 1.1-6. http://cran.r-project.org/package=lme4.

Chronis-Tuscano, A., Degnan, K.A., Pine, D.S., Perez-Edgar, K., Henderson, H.A., Diaz, Y., . . . Fox, N.A. (2009). Stable Early Maternal Report of Behavioral Inhibition Predicts Lifetime Social Anxiety Disorder in Adolescence. Journal of Amer Academy of Child \& Adolescent Psychiatry, 48(9), 928-935 910.1097/CHI.1090b1013e3181ae1009df.

Clauss, J.A., \& Blackford, J.U. (2012). Behavioral Inhibition and Risk for Developing Social Anxiety Disorder: A Meta-Analytic Study. Journal of the American Academy of Child \& Adolescent Psychiatry, 51(10), 1066-1075.e1061.

doi:http://dx.doi.org/10.1016/j.jaac.2012.08.002

Colonnesi, C., Draijer, E.M., Jan J. M. Stams, G., Van der Bruggen, C.O., Bögels, S.M., \& Noom, M.J. (2011). The Relation Between Insecure Attachment and Child Anxiety: A Meta-Analytic Review. Journal of Clinical Child \& Adolescent Psychology, 40(4), 630-645. doi:10.1080/15374416.2011.581623

Craske, M.G., Stein, M.B., Eley, T.C., Milad, M.R., Holmes, A., Rapee, R.M., \& Wittchen, H.U. (2017). Anxiety disorders. Nature Reviews Disease Primers, 3, 17024. doi:10.1038/nrdp.2017.24

Degnan, K. A., \& Fox, N. A. (2007). Behavioral inhibition and anxiety disorders: Multiple levels of a resilience process. Development and Psychopathology, 19(3), 729-746. 
Dodd, H.F., Hudson, J.L., \& Rapee, R.M. (2017). Temperament in Youth Internalizing Disorders. In Treatments for Psychological Problems and Syndromes (pp. 504-524): John Wiley \& Sons, Ltd.

Dubi, K., Rapee, R.M., Emerton, J.L., \& Schniering, C.A. (2008). Maternal Modeling and the Acquisition of Fear and Avoidance in Toddlers: Influence of Stimulus Preparedness and Child Temperament. Journal of Abnormal Child Psychology, 36(4), 499-512. doi:10.1007/s10802-007-9195-3

Eley, T.C., McAdams, T.A., Rijsdijk, F.V., Lichtenstein, P., Narusyte, J., Reiss, D., . . . Neiderhiser, J.M. (2015). The intergenerational transmission of anxiety: A children-of-twins study. American Journal of Psychiatry, 172(7), 630-637.

Enders, C. K. (2010). Applied missing data analysis: Guilford Press, New York, NY.

Erskine, H.E., Moffitt, T.E., Copeland, W.E., Costello, E.J., Ferrari, A.J., Patton, G., . . . Scott, J.G. (2015). A heavy burden on young minds: the global burden of mental and substance use disorders in children and youth. Psychological medicine, 45(07), 1551-1563. doi:doi:10.1017/S0033291714002888

Frenkel, T.I., Fox, N.A., Pine, D.S., Walker, O.L., Degnan, K.A., \& Chronis-Tuscano, A. (2015). Early childhood behavioral inhibition, adult psychopathology and the buffering effects of adolescent social networks: a twenty-year prospective study. Journal of Child Psychology and Psychiatry, 56(10), 1065-1073. doi:10.1111/jcpp.12390

Garcia Coll, C., Kagan, J., \& Reznick, J.S. (1984). Behavioral inhibition in young children. Child Development, 55(3), 1005-1019. doi:10.2307/1130152

Ginsburg, G. S., Drake, K. L., Tein, J. Y., Teetsel, R., \& Riddle, M. A. (2015). Preventing onset of anxiety disorders in offspring of anxious parents: a randomized controlled trial of a family-based intervention. American Journal of Psychiatry, 172(12), 1207-1214. 
Hirshfeld, D.R., Rosenbaum, J.F., Biederman, J., Bolduc, E.A., Faraone, S.V., Snidman, N., . . . Kagan, J. (1992). Stable behavioral inhibition and its association with anxiety disorder. Journal of the American Academy of Child \& Adolescent Psychiatry, 31(1), 103-111.

Hudson, J.L. (2017). Prevention of anxiety disorders across the lifespan. JAMA Psychiatry. doi:10.1001/jamapsychiatry.2017.2430

Hudson, J.L., Dodd, H., \& Bovopoulos, N. (2011). Temperament, Family Environment and Anxiety in Preschool Children. Journal of Abnormal Child Psychology, 39(7), 939-951. doi:10.1007/s10802-011-9502-X

Hudson, J.L., \& Dodd, H.F. (2012). Informing Early Intervention: Preschool Predictors of Anxiety Disorders in Middle Childhood. PLoS ONE, 7(8), e42359. doi:10.1371/journal.pone.0042359

Hudson, J.L., Dodd, H.F., Lyneham, H.J., \& Bovopoulous, N. (2011). Temperament and Family Environment in the Development of Anxiety Disorder: Two-Year Follow-up. Journal of the American Academy of Child and Adolescent Psychiatry, 50(12), 12551264.e1251.

Hudson, J.L., \& Rapee, R.M. (2004). From Temperament to Disorder: An Etiological Model of Generalized Anxiety Disorder. In R. G. Heimberg, C. C. Turk, \& D. S. Menin (Eds.), Generalized Anxiety Disorder: Advances in Research and Practice. New York: Guildford Press.

James, A.C., James, G., Cowdrey, F.A., Soler, A., \& Choke, A. (2015). Cognitive behavioural therapy for anxiety disorders in children and adolescents. The Cochrane Library.

Johnson, V.C., Olino, T.M., Klein, D.N., Dyson, M.W., Bufferd, S.J., Durbin, C.E., . . Hayden, E.P. (2016). A longitudinal investigation of predictors of the association between age 3 and age 6 behavioural inhibition. Journal of Research in Personality, 63, 51-61. doi:http://dx.doi.org/10.1016/j.jrp.2016.04.008 
Kuznetsova, A., Brockhoff, P.B. \& Bojesen, R.H. (2014) lmerTest: Tests for random and fixed effects for linear mixed effect models (lmer objects of lme4 package). R package version 2.0-6. http://CRAN.R-project.org/package $=1 \mathrm{me} 4$

Lazarus, R., Dodd, H., Majdandzić, M., Vente, W., Morris, T., Byrow, Y., . . Hudson, J.L. (2016). The relationship between challenging parenting behaviour and childhood anxiety disorders (Vol. 190).

Lewis-Morrarty, E., Degnan, K.A., Chronis-Tuscano, A., Pine, D.S., Henderson, H.A., \& Fox, N.A. (2015). Infant Attachment Security and Early Childhood Behavioral Inhibition Interact to Predict Adolescent Social Anxiety Symptoms. Child Development, 86(2), 598-613. doi:10.1111/cdev.12336

Lewis-Morrarty, E., Degnan, K.A., Chronis-Tuscano, A., Rubin, K.H., Cheah, C.S., Pine, D.S., ... Fox, N.A. (2012). Maternal over-control moderates the association between early childhood behavioral inhibition and adolescent social anxiety symptoms. Journal of Abnormal Child Psychology, 40(8), 1363-1373.

Manassis, K. (2001). Child-parent relations: Attachment and anxiety disorders. Anxiety disorders in children and adolescents, 255-272.

Marsh, H. W., Pekrun, R., Parker, P. D., Murayama, K. Guo, J., Dicke, T., \& Arens, A. K. (in press). The Murky Distinction Between Self-Concept and Self-Efficacy: Beware of Lurking Jingle-Jangle Fallacies. Journal of Educational Psychology.

McLeod, B.D., Wood, J.J., \& Weisz, J.R. (2007). Examining the association between parenting and childhood anxiety: A meta-analysis. Clinical Psychology Review, 27(2), 155-172.

Merikangas, K.R., He, J.-p., Burstein, M., Swanson, S.A., Avenevoli, S., Cui, L., . . . Swendsen, J. (2010). Lifetime prevalence of mental disorders in U.S. adolescents: Results from the National Comorbidity Survey Replication-Adolescent Supplement (NCS-A). 
Journal of the American Academy of Child \& Adolescent Psychiatry, 49(10), 980-989. doi:http://dx.doi.org/10.1016/j.jaac.2010.05.017

Muris, P.E.H.M., Brakel, A.M.L.v., Arntz, A., \& Schouten, E. (2011). Behavioral Inhibition as a Risk Factor for the Development of Childhood Anxiety Disorders: A Longitudinal Study. Journal of Child and Family Studies, 20, 157-170.

Ollendick, T.H., \& Grills, A.E. (2016). Perceived Control, Family Environment, and the Etiology of Child Anxiety—Revisited. Behavior Therapy, 47(5), 633-642. doi:http://dx.doi.org/10.1016/j.beth.2016.01.007

Percy, R., Creswell, C., Garner, M., O’Brien, D., \& Murray, L. (2016). Parents’ Verbal Communication and Childhood Anxiety: A Systematic Review. Clinical Child and Family Psychology Review, 19(1), 55-75. doi:10.1007/s10567-015-0198-2

Polanczyk, G.V., Salum, G.A., Sugaya, L.S., Caye, A., \& Rohde, L.A. (2015). Annual Research Review: A meta-analysis of the worldwide prevalence of mental disorders in children and adolescents. Journal of Child Psychology and Psychiatry, 56(3), 345-365.

Prior, M., Smart, D., Sanson, A., \& Oberklaid, F. (2000). Does shy-inhibited temperament in childhood lead to anxiety problems in adolescence? Journal of the American Academy of Child \& Adolescent Psychiatry, 39(4), 461-468.

R Core Team. (2013). R: A language and environment for statistical computing. R Foundation for Statistical Computing. Vienna, Austria. http://www.r-project.org/.

Rapee, R.M., Schniering, C.A., \& Hudson, J.L. (2009). Anxiety disorders during childhood and adolescence: Origins and treatment. Annual Review of Clinical Psychology, 5, 335-365.

Rubin, K.H., Burgess, K.B., Dwyer, K.M., \& Hastings, P.D. (2003). Predicting preschoolers' externalizing behaviors from toddler temperament, conflict, and maternal negativity. Developmental psychology, 39(1), 164. 
Rubin, K.H., Burgess, K.B., \& Hastings, P.D. (2002). Stability and social-behavioral consequences of toddlers' inhibited temperament and parenting behaviors. Child Development, 73(2), 483-495.

Schwartz, C.E., Snidman, N., \& Kagan, J. (1999). Adolescent social anxiety as an outcome of inhibited temperament in childhood. Journal of the American Academy of Child \& Adolescent Psychiatry, 38(8), 1008-1015.

Spence, S.H. (1998). A measure of anxiety symptoms among children. Behaviour Research \& Therapy, 36(5), 545-566.

Spence, S.H., Rapee, R., McDonald, C., \& Ingram, M. (2001). The structure of anxiety symptoms among preschoolers. Behaviour Research \& Therapy, 39(11), 1293-1316.

van Buuren, S., \& Groothuis-Oudshoorn, K. (2011). mice: Multivariate Imputation by Chained Equations in R. Journal of Statistical Software, 45(3), 1-67.

URL https://www.jstatsoft.org/v45/i03/.

van der Bruggen, C.O., Stams, G.J.J., \& Bogels, S.M. (2008). Research review: The relation between child and parent anxiety and parental control: A meta-analytic review. Journal of Child Psychology and Psychiatry, 49(12), 1257-1269. doi:http://dx.doi.org/10.1111/j.14697610.2008.01898.x

Venables, W.N., \& Ripley, B.D. (2002). Modern Applied Statistics with S. Fourth Edition. New York: Springer.

Weems, C.F. (2008). Developmental trajectories of childhood anxiety: Identifying continuity and change in anxious emotion. Developmental Review, 28(4), 488-502. doi:http://dx.doi.org/10.1016/j.dr.2008.01.001 
Supplementary Tables

Table S1.

Summary of the growth curve analysis on anxiety symptom scores (with only participants whose parent report and observation of BI agree). Bolded text shows inconsistencies in statistical significance from original analyses.

\begin{tabular}{|c|c|c|c|c|c|}
\hline & $\begin{array}{l}\text { No } \\
\text { baseline } \\
\text { predictors }\end{array}$ & $\begin{array}{l}\text { Maternal } \\
\text { lifetime } \\
\text { anxiety } \\
\text { diagnosis }\end{array}$ & $\begin{array}{l}\text { Maternal } \\
\text { over- } \\
\text { involvement }\end{array}$ & $\begin{array}{l}\text { Maternal } \\
\text { negativity }\end{array}$ & $\begin{array}{l}\text { Attachment } \\
\text { security }\end{array}$ \\
\hline Intercepts & $0.20 *$ & -0.04 & $0.21^{*}$ & $0.20 *$ & $0.26^{*}$ \\
\hline BI group & $0.95 * *$ & $0.90 * *$ & $0.92 * *$ & $0.94 * *$ & $0.96 * *$ \\
\hline $\begin{array}{l}\text { Family } \\
\text { environment }\end{array}$ & & $0.18^{* *}$ & 0.18 & 0.14 & -0.14 \\
\hline $\begin{array}{l}\text { Family } \\
\text { Environment } \mathrm{x} \\
\text { BI group }\end{array}$ & & -0.01 & -0.02 & 0.01 & -0.04 \\
\hline Ethnicity & -0.01 & -0.04 & -0.26 & -0.11 & -0.11 \\
\hline $\begin{array}{l}\text { Linear effects } \\
\text { for time }\end{array}$ & $0.20 * *$ & $0.15^{* *}$ & $0.17 * *$ & $0.19 * *$ & $0.16^{* *}$ \\
\hline $\begin{array}{l}\text { x BI group } \\
\text { x Family } \\
\text { environment }\end{array}$ & $-0.09 *$ & $\begin{array}{l}-0.17^{* *} \\
0.03\end{array}$ & $\begin{array}{l}-0.11^{* *} \\
\mathbf{0 . 0 9}\end{array}$ & $\begin{array}{l}-0.08^{*} \\
-\mathbf{0 . 0 6}\end{array}$ & $\begin{array}{l}-0.07^{*} \\
0.06\end{array}$ \\
\hline $\begin{array}{l}\text { x Family } \\
\text { environment } \mathrm{x} \\
\text { BI group }\end{array}$ & & $0.06^{*}$ & $0.12^{*}$ & 0.03 & -0.03 \\
\hline $\begin{array}{l}\text { Quadratic } \\
\text { effects for time }\end{array}$ & $-0.03 * *$ & $-0.02 * *$ & $-0.03 * *$ & $-0.03 * *$ & $-0.03 * *$ \\
\hline $\begin{array}{l}\text { x BI group } \\
\text { x Family } \\
\text { environment }\end{array}$ & 0.02 & $\begin{array}{l}\mathbf{0 . 0 1} \\
-0.00\end{array}$ & $\begin{array}{l}0.00 \\
-0.01\end{array}$ & $\begin{array}{l}0.00 \\
0.00\end{array}$ & $\begin{array}{l}0.00 \\
-0.01\end{array}$ \\
\hline $\begin{array}{l}\text { x Family } \\
\text { environment } \mathrm{x} \\
\text { BI group }\end{array}$ & & $-0.007 *$ & $-0.01^{\wedge}$ & -0.00 & 0.00 \\
\hline Intercepts & 0.70 & 0.57 & 0.63 & 0.62 & 0.62 \\
\hline $\begin{array}{l}\text { Linear slope for } \\
\text { time }\end{array}$ & 0.02 & 0.02 & 0.02 & 0.02 & 0.02 \\
\hline $\begin{array}{l}\text { Quadratic slope } \\
\text { for time }\end{array}$ & 0.00 & 0.00 & 0.00 & 0.00 & 0.00 \\
\hline
\end{tabular}


Table S2

Results of logistic regressions to assess the effect of each risk factor on the presence of an anxiety diagnosis at 8-year follow-up (results based on Multiple Imputation to handle missing data and with only participants whose parent report and observation of BI agree). Statistical significance for each analysis is identical to that reported in Table 5.

\begin{tabular}{llll}
\hline & $\begin{array}{l}\text { Before controlling } \\
\text { for baseline anxiety }\end{array}$ & $\begin{array}{l}\text { After controlling for } \\
\text { baseline anxiety }\end{array}$ & $\begin{array}{l}\text { After controlling for } \\
\text { baseline anxiety and } \\
\text { BI group }\end{array}$ \\
\cline { 2 - 4 } $\begin{array}{l}\text { Behavioral } \\
\begin{array}{l}\text { Inhibition } \\
\text { Number of maternal }\end{array}\end{array}$ & $0.56^{*}$ & $0.75^{*}$ & \\
$\begin{array}{l}\text { lifetime anxiety } \\
\text { disorders }\end{array}$ & & $0.49^{*}$ & $0.67^{*}$ \\
$\begin{array}{l}\text { Over-involvement } \\
\text { Negativity }\end{array}$ & $0.55^{*}$ & & \\
Attachment security & 0.11 & $0.49^{*}$ & 0.57 \\
\hline
\end{tabular}
Note. ${ }^{*} p<.05 ; * * p<.01$. All other values $p>.1$ 
Supplementary Tables

Table S1.

Summary of the growth curve analysis on anxiety symptom scores (with only participants whose parent report and observation of BI agree). Bolded text shows inconsistencies in statistical significance from original analyses.

\begin{tabular}{|c|c|c|c|c|c|}
\hline & $\begin{array}{l}\text { No } \\
\text { baseline } \\
\text { predictors }\end{array}$ & $\begin{array}{l}\text { Maternal } \\
\text { lifetime } \\
\text { anxiety } \\
\text { diagnosis }\end{array}$ & $\begin{array}{l}\text { Maternal } \\
\text { over- } \\
\text { involvement }\end{array}$ & $\begin{array}{l}\text { Maternal } \\
\text { negativity }\end{array}$ & $\begin{array}{l}\text { Attachment } \\
\text { security }\end{array}$ \\
\hline Intercepts & $0.20^{*}$ & -0.04 & $0.21^{*}$ & $0.20 *$ & $0.26^{*}$ \\
\hline BI group & $0.95 * *$ & $0.90 * *$ & $0.92 * *$ & $0.94 * *$ & $0.96^{* *}$ \\
\hline $\begin{array}{l}\text { Family } \\
\text { environment }\end{array}$ & & $0.18^{* *}$ & 0.18 & 0.14 & -0.14 \\
\hline $\begin{array}{l}\text { Family } \\
\text { Environment } \mathrm{x} \\
\text { BI group }\end{array}$ & & -0.01 & -0.02 & 0.01 & -0.04 \\
\hline Ethnicity & -0.01 & -0.04 & -0.26 & -0.11 & -0.11 \\
\hline $\begin{array}{l}\text { Linear effects } \\
\text { for time }\end{array}$ & $0.20 * *$ & $0.15^{* *}$ & $0.17 * *$ & $0.19 * *$ & $0.16^{* *}$ \\
\hline $\begin{array}{l}\text { x BI group } \\
\text { x Family } \\
\text { environment }\end{array}$ & $-0.09 *$ & $\begin{array}{l}-0.17^{* *} \\
0.03\end{array}$ & $\begin{array}{l}-0.11^{* *} \\
\mathbf{0 . 0 9} \wedge\end{array}$ & $\begin{array}{l}-0.08^{*} \\
-\mathbf{0 . 0 6}\end{array}$ & $\begin{array}{l}-0.07 * \\
0.06\end{array}$ \\
\hline $\begin{array}{l}\text { x Family } \\
\text { environment x } \\
\text { BI group }\end{array}$ & & $0.06^{*}$ & $0.12^{*}$ & 0.03 & -0.03 \\
\hline $\begin{array}{l}\text { Quadratic } \\
\text { effects for time }\end{array}$ & $-0.03 * *$ & $-0.02 * *$ & $-0.03 * *$ & $-0.03 * *$ & $-0.03 * *$ \\
\hline $\begin{array}{l}\text { x BI group } \\
\text { x Family } \\
\text { environment }\end{array}$ & 0.02 & $\begin{array}{l}\mathbf{0 . 0 1} \\
-0.00\end{array}$ & $\begin{array}{l}0.00 \\
-0.01\end{array}$ & $\begin{array}{l}0.00 \\
0.00\end{array}$ & $\begin{array}{l}0.00 \\
-0.01\end{array}$ \\
\hline $\begin{array}{l}\text { x Family } \\
\text { environment x } \\
\text { BI group }\end{array}$ & & $-0.007 *$ & $-0.01^{\wedge}$ & -0.00 & 0.00 \\
\hline Intercepts & 0.70 & 0.57 & 0.63 & 0.62 & 0.62 \\
\hline $\begin{array}{l}\text { Linear slope for } \\
\text { time }\end{array}$ & 0.02 & 0.02 & 0.02 & 0.02 & 0.02 \\
\hline $\begin{array}{l}\text { Quadratic slope } \\
\text { for time }\end{array}$ & 0.00 & 0.00 & 0.00 & 0.00 & 0.00 \\
\hline
\end{tabular}


Table S2

Results of logistic regressions to assess the effect of each risk factor on the presence of an anxiety diagnosis at 8-year follow-up (results based on Multiple Imputation to handle missing data and with only participants whose parent report and observation of BI agree). Statistical significance for each analysis is identical to that reported in Table 5.

\begin{tabular}{llll}
\hline & $\begin{array}{l}\text { Before controlling } \\
\text { for baseline anxiety }\end{array}$ & $\begin{array}{l}\text { After controlling for } \\
\text { baseline anxiety }\end{array}$ & $\begin{array}{l}\text { After controlling for } \\
\text { baseline anxiety and } \\
\text { BI group }\end{array}$ \\
\cline { 2 - 4 } $\begin{array}{l}\text { Behavioral } \\
\begin{array}{l}\text { Inhibition } \\
\text { Number of maternal }\end{array}\end{array}$ & $0.56^{*}$ & $0.75^{*}$ & \\
$\begin{array}{l}\text { lifetime anxiety } \\
\text { disorders }\end{array}$ & & $0.49^{*}$ & $0.67^{*}$ \\
$\begin{array}{l}\text { Over-involvement } \\
\text { Negativity }\end{array}$ & $0.55^{*}$ & & \\
Attachment security & 0.11 & $0.49^{*}$ & 0.57 \\
\hline
\end{tabular}
Note. ${ }^{*} p .05 ; * * p<.01$. All other values $p>.1$ 